\title{
Revisited: Therapeutic and toxic blood concentrations of more than 1100 drugs and other xenobiotics
}

\author{
Martin Schulz ${ }^{1,2^{*}}$ (D) Achim Schmoldt ${ }^{3}$, Hilke Andresen-Streichert ${ }^{4+}$ and Stefanie Iwersen-Bergmann ${ }^{3+}$
}

\begin{abstract}
In order to assess the significance of drug/substance levels measured in intensive care medicine and clinical and forensic toxicology as well as for therapeutic drug monitoring, it is essential that a comprehensive collection of data is readily available. We revisited and expanded our 2012 compilation of therapeutic and toxic plasma concentration ranges as well as half-lives of now more than 1100 drugs and other xenobiotics.

Data have been abstracted from original papers, text books, and previous compilations and have been completed with data collected in our own forensic and clinical toxicology laboratories. We compiled the data presented in the table and the corresponding annotations over the past 30+ years. A previous compilation was completely doublechecked, revised, and updated, if necessary. In addition, more than 200 substances, especially drugs who have been introduced since 2012 to the market as well as illegal drugs and other xenobiotics which became known to cause intoxications were added. We carefully referenced all data. Moreover, the annotations providing details were updated and revised, when necessary.

For more than 1100 drugs and other xenobiotics, therapeutic ("normal") and, if data was available, toxic, and comatose-fatal plasma/blood concentrations as well as elimination half-lives were compiled in a table.

In case of intoxications, the blood concentration of the substance and/or metabolite better predicts the clinical severity of the case when compared to the assumed amount and time of ingestion. Comparing and contrasting the clinical case against the data provided, including the half-life, may support the decision for or against further intensive care. In addition, the data provided are useful for the therapeutic monitoring of pharmacotherapies, to facilitate the diagnostic assessment and monitoring of acute and chronic intoxications as well as to support forensic and clinical expert opinions.
\end{abstract}

Keywords: Critical care, Drug monitoring, Drug-related side effects and adverse reactions, Humans, Overdose, Intoxication, Xenobiotics/blood, Xenobiotics/toxicity

\footnotetext{
* Correspondence: m.schulz@fu-berlin.de

Hilke Andresen-Streichert and Stefanie Iwersen-Bergmann are joint last authors

${ }^{1}$ Drug Commission of German Pharmacists (AMK), Heidestraße 7, 10557

Berlin, Germany

${ }^{2}$ Institute of Pharmacy, Freie Universität Berlin, Kelchstraße 31, 12169 Berlin, Germany

Full list of author information is available at the end of the article
}

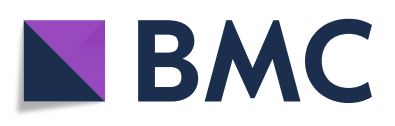

(c) The Author(s). 2020 Open Access This article is licensed under a Creative Commons Attribution 4.0 International License, which permits use, sharing, adaptation, distribution and reproduction in any medium or format, as long as you give appropriate credit to the original author(s) and the source, provide a link to the Creative Commons licence, and indicate if changes were made. The images or other third party material in this article are included in the article's Creative Commons licence, unless indicated otherwise in a credit line to the material. If material is not included in the article's Creative Commons licence and your intended use is not permitted by statutory regulation or exceeds the permitted use, you will need to obtain permission directly from the copyright holder. To view a copy of this licence, visit http://creativecommons.org/licenses/by/4.0/. The Creative Commons Public Domain Dedication waiver (http://creativecommons.org/publicdomain/zero/1.0/) applies to the data made available in this article, unless otherwise stated in a credit line to the data. 


\section{Introduction}

Drug overdose has become the leading cause of death from injury in the USA [1]. In 2017, more than 2.6 million closed encounters were logged by the American Association of Poison Control Centers' National Poison Data System and 2.12 million were related to human exposures. Although the total encounters showed a $3.8 \%$ decline from 2016, human exposures with more serious outcomes increased $3.1 \%$. Consistent with previous years, the top five substance classes most frequently involved in all human exposures included three drug classes: analgesics (11.1\%), household cleaning substances (7.4\%), cosmetics/personal care products (6.8\%), sedatives/hypnotics/antipsychotics (5.7\%), and antidepressants (5.0\%) [2]. According to the UK's National Poisons Information Service Annual Report 2017/2018, around 160,000 hospital presentations occur annually as a result of poisoning, most frequently in the context of deliberate self-harm [3].

In case of intoxication or poisoning, the concentration of the ingested substance and/or metabolite in plasma/ serum better predicts the clinical severity of the case and the potential outcome when compared to the assumed amount and time of ingestion. In addition, it is recommended that plasma concentrations of drugs having a narrow therapeutic range or with a highly variable response (such as in psychiatry) have to be measured and monitored. Apart from acute and chronic intoxications, it is indicated to draw blood samples for the following reasons: if doses are high and borderline, if signs of over-dosage occur although the dose is within normal range (e.g. genetic polymorphism), if there is no efficacy although the dose is correct, or if medication nonadherence can be expected [4].

In general, blood concentrations of drugs at steady state are retrievable from the dosage and pharmacokinetic data. However, sufficient pharmacokinetic data are often not available. Moreover, searching, retrieving, reading, analysing, and interpreting the relevant pharmacological, toxicological, and critical care literature in case of acute intoxications in daily intensive care practice are time-consuming and may delay or even mislead optimal clinical decisions. Therefore, it makes sense to offer a carefully referenced compilation of therapeutic and toxic plasma concentration ranges, as well as half-lives, of a large number of drugs and other xenobiotics for quick and comprehensive information [4].

\section{Materials and methods}

The data presented in the table and the corresponding annotations (Additional file 1) have been developed over the past 30+ years. A previous compilation [4] has been completely revised and updated where necessary. In addition, more than 200 substances, especially drugs that have been introduced since then were added. Furthermore, we included new psychoactive substances (NPS), marketed as 'legal highs', as well as other illegal drugs which became known to cause intoxications. All data were carefully referenced. Moreover, the annotations providing details were updated and revised, if necessary.

Reviews, text books, compilations of other authors (mainly [5-25]), and most importantly, original publications concerning individual drugs, pharmacokinetic studies, and case reports have been used to set up and keep the database updated. Experience gained over more than 30 years from working in the clinical and forensic toxicological field contributed to the data presented.

The substances were selected by clinical and toxicological aspects, by frequency of prescribing or (mis-)use and other matters in the area of intensive care medicine as well as clinical and forensic toxicology.

The following clinical categories were used for grouping analytical data:

Therapeutic: blood (plasma or serum) concentrations observed following therapeutically effective doses; no or only minimal side effects (drugs); "normal": concentrations associated with no or only minimal toxic effects (other xenobiotics or environmental exposure) or achieved by a typical dosing regimen (illegal drugs).

Toxic: blood (plasma/serum) concentrations producing toxicity or clinically relevant adverse effects. Comatose-fatal: blood (plasma/serum for comatose) concentrations and whole blood (for fatal) concentrations reported to have caused coma and death, respectively. Whether published data for deaths refer to levels measured ante-mortem or post-mortem (femoral or heart blood) is, however, often unknown.

\section{Results and discussion}

For more than 1100 drugs and other xenobiotics, therapeutic ("normal") and, if data was available, toxic, and comatose-fatal plasma/blood concentrations and elimination half-lives were compiled in one table (Additional file 1).

The compilation includes data for centrally active substances (e.g. anaesthetics, antidepressants, antiepileptics, antiparkinson drugs, antipsychotics, anxiolytics, hypnotics, lithium, opioids, sedatives, stimulants), cardiovascular drugs (e.g. angiotensin-converting enzyme inhibitors, angiotensin receptor antagonists [sartanes], antiarrhythmics, anticoagulants, antihypertensives, antiplatelets, beta blockers, calcium-channel blockers, cardiac glycosides, diuretics, lipid lowering drugs, nitrates), antimicrobial agents (e.g. antibiotics, antimalarials, antimycotics, antiretrovirals), and anabolics, non-opioid analgesics including nonsteroidal anti-inflammatory drugs, antiasthmatics, anticancer drugs, antidiabetics, antihistamines, corticosteroids, 


\section{- In overdose and intoxication, the concentration of the ingested substance in blood better predicts the clinical severity of the case when compared to the assumed amount and time of ingestion. \\ - The most current and comprehensive single source of data for more than 1,100 drugs and other xenobiotics is provided. \\ - It can support the clinical decision making in case of acute or chronic intoxications. \\ - Comparing and contrasting the clinical case against the data provided, including the half-life, may support the decision for or against further intensive care.}

Fig. 1 Summary findings

immunosuppressants, local anaesthetics, muscle relaxants, phosphodiesterase inhibitors, and vitamins, among others (Fig. 1).

In addition and if data were available, other relevant xenobiotics such as controlled substances, illegal and recreational drugs, including new psychoactive substances, heavy metals, and pesticides, among others were listed.

To the best of our knowledge, this compilation is the most current and comprehensive single source of data, necessary to support the clinical decision-making and assessing blood concentrations in case of acute or chronic intoxications. Inter-individual deviation is, however, high. Therefore, any data listed can only be taken as an orientation.

Often, it is not possible to find the threshold between the therapeutic and toxic concentration for the specific patient. This is for instance the case if tolerance (especially true for all opioids), drug/drug-interactions, or additional diseases are involved. In order to keep the overall context clear, we preferred not to go into further details.

Many data about "comatose" or even "fatal" plasma/blood concentrations are consciously oriented on life threatening or lethal intoxications where low plasma/blood concentrations were detected. Considering these data may prevent underestimation of actual or potential dangers in clinical cases. Many intoxicated patients survived even with significantly higher plasma concentrations.

It is also difficult to relate the concentrations to the clinical picture because the interval between intake of the drug and drawing a blood sample is frequently unknown. In any case, it is more reliable to have the correct concentration measured rather than assuming how much drug/substance has been taken.
For a variety of data representing lethal cases, it is not known whether ante- or post-mortem, that is, (venous) femoral or heart blood levels were measured. If this information is unknown, we refrained from mentioning this detail.

Elimination half-lives are statistically more reliable than data gathered in case of intoxications. Yet even with this data, substantial deviation occurs. In addition, most pharmacokinetic parameters are retrieved from healthy subjects after application of relatively low doses. The data indicated generally deals with the terminal elimination half-life.

\section{Conclusions}

In case of acute or chronic intoxications, the concentration of the ingested substance and/or metabolite in blood much better predicts the clinical severity of the case when compared to the assumed amount and time of ingestion. Comparing and contrasting the clinical case against the data provided, including the half-life, may support the decision for or against further intensive care. In addition, the data provided are useful for the therapeutic monitoring of pharmacotherapies, to facilitate the diagnostic assessment and monitoring of acute and chronic intoxications as well as to support forensic and clinical expert opinions.

\section{Supplementary information}

Supplementary information accompanies this paper at https://doi.org/10. 1186/s13054-020-02915-5.

Additional file 1. Therapeutic ("normal"), toxic, and comatose-fata blood-plasma concentrations ( $\mathrm{mg} / \mathrm{L}$, if not stated otherwise) in man. A table containing data for more than 1100 drugs and other xenobiotics in man including annotations and references. 


\section{Acknowledgements}

We thank Margit Schmidt, AMK, Berlin, for her most valuable help in searching and retrieving the literature and in preparing, updating, and formatting this manuscript and, more importantly, the additional file.

\section{Authors' contributions}

MS had the original idea, critically analysed the available data, reviewed other compilations and textbooks, searched and retrieved most of the original papers, and drafted the manuscript. AS provided data of several thousand cases analysed during his time as head of the toxicological laboratory, Institute of Legal Medicine, University Medical Centre HamburgEppendorf. SIB and HAS critically reviewed all data, searched and analysed all available review sources, and provided data as well as references for new substances including case reports analysed in their toxicological laboratories. All authors developed and published the previous compilation [4]. All authors read and approved the final manuscript.

\section{Funding}

This work received no specific funding. Publication costs were funded by the Drug Commission of German Pharmacists (AMK).

\section{Availability of data and materials}

Not applicable.

\section{Ethics approval and consent to participate}

Not applicable.

\section{Consent for publication}

Not applicable.

\section{Competing interests}

The authors declare that they have no competing interests.

\section{Author details}

'Drug Commission of German Pharmacists (AMK), Heidestraße 7, 10557 Berlin, Germany. ${ }^{2}$ Institute of Pharmacy, Freie Universität Berlin, Kelchstraße 31, 12169 Berlin, Germany. Institute of Legal Medicine, University Medical Centre Hamburg-Eppendorf, Butenfeld 34, 22529 Hamburg, Germany. ${ }^{4}$ Department of Forensic Toxicology, Institute of Legal Medicine, Faculty of Medicine, University of Cologne, Melatengürtel 60-62, 50823 Cologne, Germany.

\section{Received: 6 March 2020 Accepted: 22 April 2020}

Published online: 06 May 2020

\section{References}

1. McCarthy M. Drug overdose has become leading cause of death from injury in US. Brit Med J. 2015;350:h3328.

2. Gummin DD, Mowry JB, Spyker DA, Brooks DE, Osterthaler KM, Banner W. 2017 Annual Report of the American Association of Poison Control Centers' National Poison Data System (NPDS): 35th Annual Report. Clin Toxicol (Phila). 2018;56(12):1213-415.

3. Gordon L, Jackson G, Sandilands EA. National Poisons Information Service Annual Report 2017/2018. [http://www.npis.org/NPISAnnualReport2017-18. pdf]. Accessed 20 Feb 2020.

4. Schulz M, Iwersen-Bergmann S, Andresen $\mathrm{H}$, Schmoldt A. Therapeutic and toxic blood concentrations of nearly 1,000 drugs and other xenobiotics. Crit Care. 2012;16:R136.

5. Baselt RC. Disposition of toxic drugs and chemicals in man. 11th ed. Seal Beach: Biomedical Publications; 2017.

6. Launiainen T, Ojanperä I. Drug concentrations in post-mortem femoral blood compared with therapeutic concentrations in plasma. Drug Test Anal. 2014;6(4):308-16.

7. Druid H, Holmgren P. A compilation of fatal and control concentrations of drugs in postmortem femoral blood. J Forensic Sci. 1997:42:79-87.

8. IBM Micromedex ${ }^{\circledast}$ DRUGDEX ${ }^{\circledast}$ (electronic version). IBM Watson Health, Greenwood Village, Colorado, USA. Available at https://www. micromedexsolutions.com/ (updated periodically).

9. Hiemke C, Bergemann N, Clement HW, Conca A, Deckert J, Domschke K, et al. Consensus guidelines for therapeutic drug monitoring in neuropsychopharmacology: update 2017. Pharmacopsychiatry. 2018;51(1/ 02):9-62.

10. Meyer FP. Indicative therapeutic and toxic drug concentrations in plasma: a tabulation. Int J Clin Pharmacol Ther. 1994;32(2):71-81.

11. Moffat AC, Jackson JV, Moss MS, Widdop B. Clarke's isolation and identification of drugs in pharmaceuticals, body fluids, and post-mortem material. 2nd ed. London: Pharmaceutical Press; 1986.

12. Ketola RA, Ojanperä I. Summary statistics for drug concentrations in postmortem femoral blood representing all causes of death. Drug Test Anal. 2019;11(9):1326-37.

13. Repetto MR, Repetto M. Therapeutic, toxic, and lethal concentrations in human fluids of 90 drugs affecting the cardiovascular and hematopoietic systems. J Toxicol Clin Toxicol. 1997;35(4):345-51.

14. Repetto MR, Repetto M. Habitual, toxic, and lethal concentrations of 103 drugs of abuse in humans. J Toxicol Clin Toxicol. 1997;35(1):1-9.

15. Repetto MR, Repetto M. Therapeutic, toxic, and lethal concentrations of 73 drugs affecting respiratory system in human fluids. J Toxicol Clin Toxicol. 1998;36(4):287-93.

16. Repetto MR, Repetto M. Concentrations in human fluids: 101 drugs affecting the digestive system and metabolism. J Toxicol Clin Toxicol. 1999;37(1):1-9.

17. Stead AH, Moffat AC. A collection of therapeutic, toxic and fatal blood drug concentrations in man. Hum Toxicol. 1983;2(3):437-64.

18. Uges DRA. Orientierende Angaben zu therapeutischen und toxischen Konzentrationen von Arzneimitteln und Giften in Blut, Serum oder Urin [in German]. Weinheim: VCH; 1990.

19. Medical Economics Staff. USP DI: Drug Information for the Health Care Professional. 23rd ed. Englewood: US Pharmacopoeial Convention Inc., Micromedex Inc:; 2003.

20. Neels HM, Sierens AC, Naelaerts K, Scharpe SL, Hatfield GM, Lambert WE. Therapeutic drug monitoring of old and newer anti-epileptic drugs. Clin Chem Lab Med. 2004;42(11):1228-55.

21. Regenthal R, Krueger M, Koeppel C, Preiss R. Drug levels: therapeutic and toxic serum/plasma concentrations of common drugs. J Clin Monit Comput. 1999;15(7-8):529-44.

22. Winek CL, Wahba WW, Winek CL Jr, Balzer TW. Drug and chemical bloodlevel data 2001. Forensic Sci Int. 2001;122(2-3):107-23.

23. Musshoff F, Padosch S, Steinborn S, Madea B. Fatal blood and tissue concentrations of more than 200 drugs. Forensic Sci Int. 2004;142(2-3):161210.

24. Thomas L (ed.): Labor und Diagnose [in German]. 8th ed. 2012. TH-Books, Frankfurt/Main.

25. Sutherland JJ, Morrison RD, McNaughton CD, Daly TM, Milne SB, Daniels JS, et al. Assessment of patient medication adherence, medical record accuracy, and medication blood concentrations for prescription and overthe-counter medications (Supplementary Online Content eTable 2). JAMA Netw Open. 2018;1(7):e184196.

\section{Publisher's Note}

Springer Nature remains neutral with regard to jurisdictional claims in published maps and institutional affiliations. 